\title{
Badania składu ilościowego i jakościowego grzybów zasiedlających nasiona soi (Glycine max L.)
}

\section{Study on the quantitative and qualitative of fungi colonizing soybeans (Glycine max L.)}

\author{
Katarzyna Janda, Jolanta Wolska \\ Zakład Biochemii i Żywienia Człowieka Pomorskiego Uniwersytetu Medycznego w Szczecinie \\ ul. Broniewskiego 24, 71-460 Szczecin \\ Kierownik: prof. dr hab. n. med. Ewa Stachowska
}

\section{SUMMARY}

The aim of study was to analyse the qualitative and quantitative composition of fungi in soybeans on RBCA, YpSs, and DG18 culture media at 25,37 and $45^{\circ} \mathrm{C}$. The analysis included 15 samples of soybeans. The highest number of mould species (23) were isolated on RBCA at $25^{\circ} \mathrm{C}$, followed by xerophilic species (20) on DG18 at $25^{\circ} \mathrm{C}$, and mesophilic (13) and

\section{STRESZCZENIE}

Celem pracy była ocena składu ilościowego i jakościowego grzybów zasiedlających nasiona soi na podłożu RBCA, YpSs, DG18 w temperaturze $25,37,45^{\circ} \mathrm{C}$. Materiałem badawczym było 15 próbek nasion soi. Najwięcej gatunków (23) wyizolowano na pożywce RBCA w $25^{\circ} \mathrm{C}$, nieco mniej gatunków kserofilnych (20) na DG18 w $25^{\circ} \mathrm{C}$, a w dalszej kolejności na YpSs thermophilic species (4) on YpSs medium at $37^{\circ}$ and $45^{\circ} \mathrm{C}$, respectively. Ninety-five strains belonging to 40 species were isolated from soybean samples. The predominant species were Penicillium chrysogenum and Eurotium herbariorum. This study revealed new species of mycobiota not previously isolated from soybeans.

Key words: moulds, soybeans, Glycine max.

\section{WSTĘP}

Drobnoustroje, zwłaszcza grzyby strzępkowe, ze względu na zdolności adaptacyjne do skrajnych warunków środowiska, przysparzają problemów w wielu dziedzinach życia i gospodarki. Są potencjalnie istotnym zagrożeniem w przemyśle spożywczym, przyczyniają się do psucia oraz obniżania jakości surowców oraz produktów żywnościowych, powodując przy tym znaczne straty ekonomiczne $[1,2,3,4]$. Ich obecność w środowisku może być przyczyną uczuleń i chorób zarówno ludzi, jak i zwierząt [2].

Dostępne są prace na temat tych drobnoustrojów zasiedlających środowiska o niskiej wilgotności, takie jak ziarna różnych gatunków roślin zbożowych i ich przetwory [5, 6, 7, $8,9,10,11,12]$, ziarno kawy $[13,14]$, kakao $[15,16]$, orzechy $[12$, $17,18,19,20]$, przyprawy i zioła $[21,22,23,24,25,26]$, a także świeże oraz suszone owoce i warzywa [27, 28, 29, 30, 31, 32]. Dowiedziono, że również nasiona roślin oleistych są źródłem licznych gatunków pleśni [3, 33, 34, 35, 36, 37, 38, 39, 40, 41, 42, $43,44,45,46]$.

Celem pracy było określenie występowania grzybów pleśniowych w nasionach soi (Glycine max L.). w $37^{\circ} \mathrm{C}$ i $45^{\circ} \mathrm{C}$ (odpowiednio 13 i 4). Z nasion soi wyizolowano 95 szczepów należących do 40 gatunków. Gatunkami dominującymi były Penicillium chrysogenum i Eurotium herbariorum. Przeprowadzone badania wzbogaciły mykocenozę nasion soi o nowe gatunki, których dotychczas nie izolowano z tego surowca.

Słowa kluczowe: grzyby pleśniowe, nasiona soi, Glycine max.

\section{MATERIAŁ I METODY}

Materiałem badawczym było 15 próbek suchych nasion soi (Glycine max L.), bez śladów zapleśnienia, które pochodziły z sieci handlowej. W celu dokładnego określenia składu ilościowego i jakościowego grzybów wykonywano posiewy metodą kolejnych rozcieńczeń. Do wykonania 10-krotnych rozcieńczeń wykorzystano jałowy roztwór o składzie: 8,5 g $\mathrm{NaCl}, 1,0$ g peptonu, $1000 \mathrm{~cm}^{3}$ wody destylowanej [47]. Wykorzystano trzy pożywki i trzy temperatury inkubacji: 1) RBCA (Rose Bengal Chloramphenicol Agar): pepton mykologiczny 5,0 g, glukoza 10,0 g, $\mathrm{K}_{2} \mathrm{HPO}_{4} 1,0 \mathrm{~g}$, $\mathrm{MgSO}_{4} \cdot 7 \mathrm{H}_{2} \mathrm{O}$ 0,5 g, róż bengalski 0,05 g, agar 15,0 g, woda destylowana 1000,0 cm³ pH $7,2 \mathrm{w} 25^{\circ} \mathrm{C}, 2$ ) YpSs (Yeast Powder Soluble Starch Agar; Emerson's agar medium): ekstrakt drożdżowy 4,0 g, skrobia rozpuszczalna $15,0 \mathrm{~g}, \mathrm{~K}_{2} \mathrm{HPO}_{4} 1,0 \mathrm{~g}$, $\mathrm{MgSO}_{4} \cdot 7 \mathrm{H}_{2} \mathrm{O} 0,5 \mathrm{~g}$, agar $15,0 \mathrm{~g}$, woda destylowana 1000,0 cm $\mathrm{cm}^{3} \mathrm{pH} 7,0 \mathrm{w} 37^{\circ} \mathrm{C}$ do określenia spektrum grzybów mezofilnych oraz $\mathrm{w} 45^{\circ} \mathrm{C}$ do określenia składu grzybów termofilnych i termotolerancyjnych, 3) DG18 (Dichloran Glicerol Agar): pepton 5,0 g, glukoza 10,0 g, $\mathrm{KH}_{2} \mathrm{PO}_{4}$ $1,0 \mathrm{~g}, \mathrm{MgSO}_{4} \cdot 7 \mathrm{H}_{2} \mathrm{O}$ 0,5 g, dichloran 0,002 g, agar $15,0 \mathrm{~g}$, woda destylowana 1000,0 $\mathrm{cm}^{3}$; pH 5,6 w $25^{\circ} \mathrm{C}$ do określenia spektrum 
TABELA 1. Liczba grzybów wyrosłych z nasion soi w zależności od zastosowanej pożywki i temperatury inkubacji

\begin{tabular}{|c|c|c|c|c|}
\hline \multirow{2}{*}{$\begin{array}{c}\text { Pożywka i temperatura } \\
\text { inkubacji }\end{array}$} & Średnia & Minimum & Maksimum & \multirow{2}{*}{$\begin{array}{l}\text { Współczynnik } \\
\text { zmienności }\end{array}$} \\
\hline & & jtk.100 $\mathrm{g}^{-1}$ & & \\
\hline $\mathrm{DG} 18 \mathrm{w} 25^{\circ} \mathrm{C}$ & $1,4 \cdot 10^{5}$ & $3,8 \cdot 10^{2}$ & $1,2 \cdot 10^{6}$ & 2,39 \\
\hline $\mathrm{RBCA} w 25^{\circ} \mathrm{C}$ & $4,2 \cdot 10^{4}$ & $1,0 \cdot 10^{2}$ & $6,0 \cdot 10^{5}$ & 3,71 \\
\hline YpSs w $37^{\circ} \mathrm{C}$ & $3,2 \cdot 10^{2}$ & $2,5 \cdot 10^{1}$ & $1,6 \cdot 10^{3}$ & 1,26 \\
\hline
\end{tabular}

grzybów kserotolerancyjnych i kserofilnych. Do wszystkich pożywek dodawano chloramfenikol w ilości $100 \mathrm{mg} / 1000,0 \mathrm{~cm}^{3}$ podłoża [47]. Posiewy wykonywano w trzech powtórzeniach. Czyste kultury grzybów oznaczano do gatunku na podstawie ich cech makro- i mikromorfologicznych $[48,49,50,51,52$, 53, 54, 55]. Do identyfikacji szczepów wykorzystano technikę mikrohodowli oraz preparaty wykonane w laktofenolu z dodatkiem barwnika cotton blue i w PVA [56]. Udział poszczególnych gatunków w mykobiocenozie nasion określono jako stosunek szczepów danego gatunku do ogólnej ilości wyodrębnionych szczepów. Liczbę grzybów przedstawiono jako jednostki tworzące kolonie w 100 g świeżej masy nasion (jtk•100 g ${ }^{-1}$ ś. m). Otrzymane wyniki poddano analizie statystycznej przy użyciu arkusza kalkulacyjnego Excel oraz programu Statistica 8.0.

\section{OMÓWIENIE WYNIKÓW I DYSKUSJA}

Próbki nasion soi różniły się między sobą liczbą zasiedlających je grzybów. Największe różnice pod względem liczby grzybów stwierdzono na podłożu RBCA w $25^{\circ} \mathrm{C}\left(1,0 \cdot 10^{2}-6,0 \cdot 10^{5}\right.$ jtk $/ 100 g^{-1}$.), zaś najmniejsze na YpSs w $37^{\circ} \mathrm{C}\left(2,5^{\circ} 10^{1}-1,6 \cdot 10^{3}\right.$ jtk·100g $\left.{ }^{-1}\right)$. Największą liczbę grzybów $\left(1,4 \cdot 10^{5} \mathrm{jtk} \cdot 100 \mathrm{~g}^{-1}\right)$ wyizolowano na podłożu DG18 w $25^{\circ} \mathrm{C}$ (tab. 1), w związku z czym podłoże to wydaje się być najlepszym do określania liczebności grzybów mikroskopowych zasiedlających nasiona soi.

Skład jakościowy grzybów zasiedlających nasiona soi przedstawiono w tabeli 2. Łącznie wyizolowano 95 szczepów należących do 40 gatunków. Liczba gatunków w próbkach wahała się w zakresie 2-14. Gatunkami o częstości izolowania powyżej 20\% były: Penicillium chrysogenum (100\%), Eurotium herbariorum (73,3\%), Aspergillus fumigatus (46,7\%), Aspergillus versicolor (40\%), Aspergillus sydowii $(26,7 \%)$ oraz Rhizopus oryzae $(26,7 \%)$. Udział tych gatunków w mykobiocenozie nasion soi (w stosunku do ogółu szczepów) mieścił się w zakresie od 4,2\% (Aspergillus sydowii, Rhizopus oryzae) do 15,8\% (Penicillium chrysogenum).

Skład jakościowy grzybów wyizolowanych z nasion soi na poszczególnych pożywkach i w określonych temperaturach przedstawiono w tabeli 3 .

Najwięcej gatunków (23) wyizolowano na pożywce RBCA w $25^{\circ} \mathrm{C}$, nieco mniej gatunków na DG18 w $25^{\circ} \mathrm{C}(20)$, a w dalszej kolejności na YpSs w $37^{\circ} \mathrm{C}$ i $45^{\circ} \mathrm{C}$ (odpowiednio 13 i 4). Badania wskazują, że do wyodrębnienia z nasion soi jak największej liczby gatunków najodpowiedniejsza jest temperatura $25^{\circ} \mathrm{C}$ oraz standardowa pożywka RBCA, a także DG18, która polecana jest do wyodrębniania grzybów kserofilnych.

Z zestawienia przedstawionego $w$ tabeli 4 wynika, że dotychczas z nasion soi wyodrębniono 74 rodzaje grzybów. Badania własne dowiodły, że nasiona tego gatunku oprócz wymienionych grzybów zasiedlają również: Aspergillus versicolor, A. penicillioides, A. tamarii, A. unguis, Cladosporium sphaerospermum, Emericella nidulans, Geomyces pannorum, Metarhizium anisopliae, Mucor circinelloides, Penicillium arenicola, P. canescens, P. commune, P. cyclopium, P. hordei, P. jensenii, P. miczynskii, P. nigricans, P. radicicola, P. spinulosum, P. verrucosum, Rhizopus oryzae oraz Wardomyces columbinus.

Należy podkreślić, że autorzy zajmujący się określaniem mycobiocenozy nasion soi najczęściej stosowali jedno podłoże mikrobiologiczne i jedną temperaturę inkubacji. Można więc przypuszczać, że wyizolowanie z nasion soi gatunków, które dotychczas nie były z nich wyodrębniane, możliwe było dzięki temu, iż w niniejszej pracy zastosowano różne pożywki, a inkubacje prowadzono w trzech temperaturach. Pożywki różniły się między sobą składnikami pokarmowymi, wartością pH i aktywności wody. Te czynniki w połączeniu w rożna temperaturą hodowli pozwoliły na wyodrębnienie szerokiego spektrum grzybów mikroskopowych, włącznie z gatunkami kserofilnymi, termotolerancyjnymi i termofilnymi.

\section{WNIOSKI}

1. Nasiona soi bez widocznych oznak zapleśnienia, dostępne w sieci handlowej, okazały się bogatym źródłem wielu gatunków grzybów strzępkowych.

2. Gatunkami dominującymi były Penicillium chrysogenum i Eurotium herbariorum, grzyby o potencjalnych właściwościach toksynotwórczych.

3. Otrzymane wyniki wskazują, że grzyby pleśniowe występujące na nasionach soi stanowią potencjalne źródło zanieczyszczenia mikrobiologicznego żywności.

\section{PISMIENNICTWO}

1. Adamczak M., Bednarski W.: Metody pomiaru aktywności lipolitycznej lipaz w mleku i przetworach mleczarskich. Przegląd Mleczarski. 2002, 10, 442-447.

2. De Lucca A.J.: Harmful fungi in both agriculture and medicine. Rev Iberoam Micol. 2007, 24 (1), 3-13. 
TABELA 2. Skład jakościowy grzybów wyizolowanych z nasion soi w zależności od pożywki i temperatury inkubacji

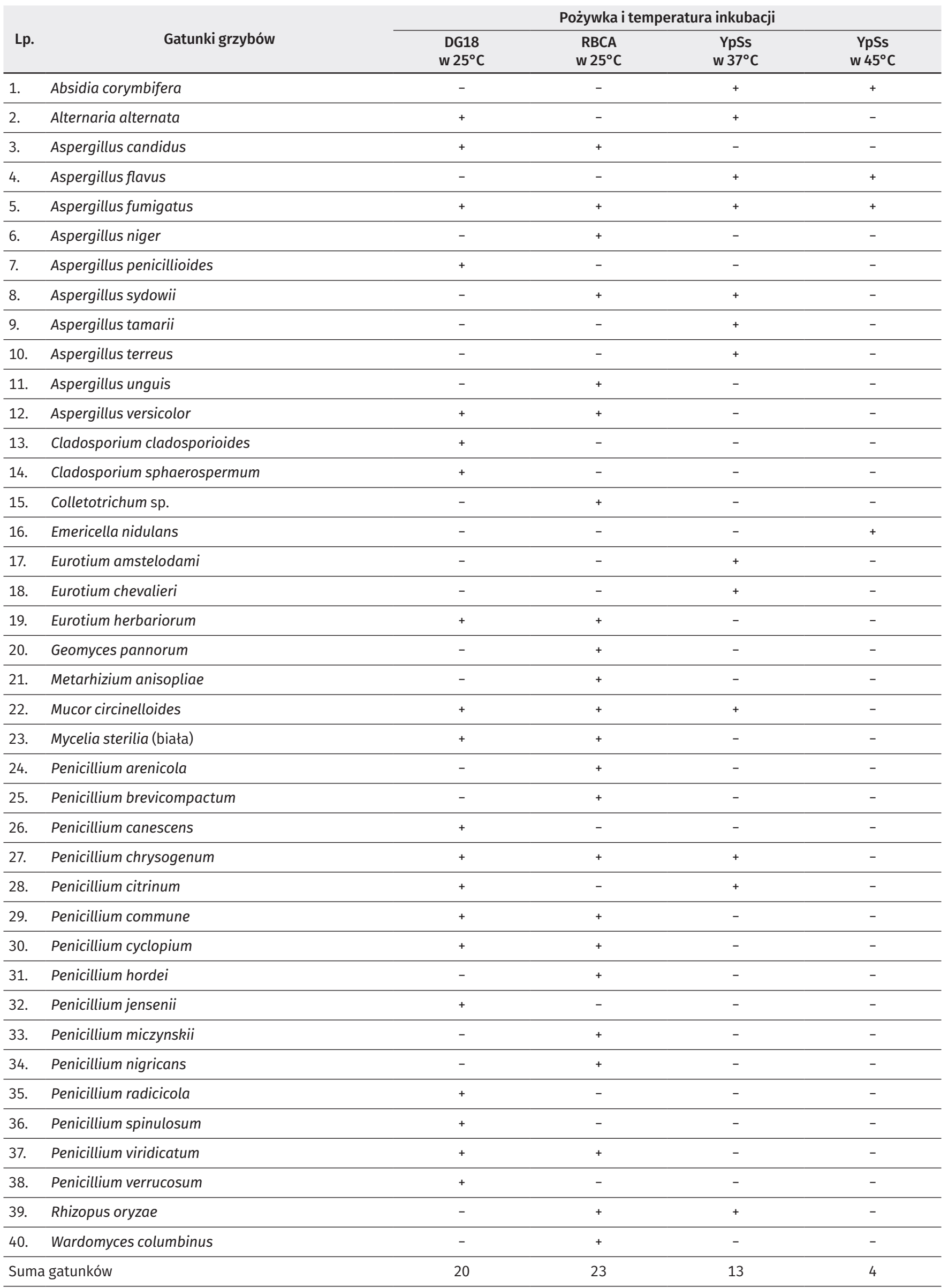


TABELA 3. Skład jakościowy grzybów mikroskopowych w próbkach nasion soi

\begin{tabular}{|c|c|c|c|c|}
\hline L.p. & Gatunki grzybów & $\begin{array}{c}\text { Liczba próbek, w których } \\
\text { stwierdzono obecność } \\
\text { gatunku }\end{array}$ & $\begin{array}{c}\text { Częstość } \\
\text { występowania } \\
(\%)^{\star}\end{array}$ & $\begin{array}{c}\text { Udział w mykobiocenozie } \\
(\%)\end{array}$ \\
\hline 1. & Penicillium chrysogenum & 15 & 100,0 & 15,8 \\
\hline 2. & Eurotium herbariorum & 11 & 73,3 & 11,6 \\
\hline 3. & Aspergillus fumigatus & 7 & 46,7 & 7,4 \\
\hline 5. & Aspergillus sydowii & 4 & 26,7 & 4,2 \\
\hline 6. & Rhizopus oryzae & 4 & 26,7 & 4,2 \\
\hline 7. & Aspergillus unguis & 3 & 20,0 & 3,2 \\
\hline 8. & Mycelia sterilia (biała) & 3 & 20,0 & 3,2 \\
\hline 10. & Alternaria alternata & 2 & 13,3 & 2,1 \\
\hline 11. & Aspergillus candidus & 2 & 13,3 & 2,1 \\
\hline 12. & Aspergillus flavus & 2 & 13,3 & 2,1 \\
\hline 13. & Emericella nidulans & 2 & 13,3 & 2,1 \\
\hline 14. & Penicillium citrinum & 2 & 13,3 & 2,1 \\
\hline 15. & Penicillium commune & 2 & 13,3 & 2,1 \\
\hline 16. & Penicillium cyclopium & 2 & 13,3 & 2,1 \\
\hline 17. & Penicillium viridicatum & 2 & 13,3 & 2,1 \\
\hline 18. & Absidia corymbifera & 1 & 6,7 & 1,1 \\
\hline 19. & Aspergillus niger & 1 & 6,7 & 1,1 \\
\hline 21. & Aspergillus tamarii & 1 & 6,7 & 1,1 \\
\hline 22. & Aspergillus terreus & 1 & 6,7 & 1,1 \\
\hline 23. & Cladosporium cladosporioides & 1 & 6,7 & 1,1 \\
\hline 24. & Cladosporium sphaerospermum & 1 & 6,7 & 1,1 \\
\hline 25. & Colletotrichum sp. & 1 & 6,7 & 1,1 \\
\hline 26. & Eurotium amstelodami & 1 & 6,7 & 1,1 \\
\hline 27. & Eurotium chevalieri & 1 & 6,7 & 1,1 \\
\hline 28. & Geomyces pannorum & 1 & 6,7 & 1,1 \\
\hline 29. & Metarhizium anisopliae & 1 & 6,7 & 1,1 \\
\hline 30. & Mucor circinelloides & 1 & 6,7 & 1,1 \\
\hline 31. & Penicillium arenicola & 1 & 6,7 & 1,1 \\
\hline 32. & Penicillium brevicompactum & 1 & 6,7 & 1,1 \\
\hline 33. & Penicillium canescens & 1 & 6,7 & 1,1 \\
\hline 34. & Penicillium hordei & 1 & 6,7 & 1,1 \\
\hline 35. & Penicillium jensenii & 1 & 6,7 & 1,1 \\
\hline 36. & Penicillium nigricans & 1 & 6,7 & 1,1 \\
\hline 37. & Penicillium radicicola & 1 & 6,7 & 1,1 \\
\hline 38. & Penicillium spinulosum & 1 & 6,7 & 1,1 \\
\hline 39. & Penicillium verrucosum & 1 & 6,7 & 1,1 \\
\hline
\end{tabular}

* \% próbek, w których stwierdzono występowanie grzyba 
TABELA 4. Grzyby wyodrębnione z nasion soi $[34,35$, 37, 38, 42, 43, 45, 46, 57, 58, 59, 60, 61]

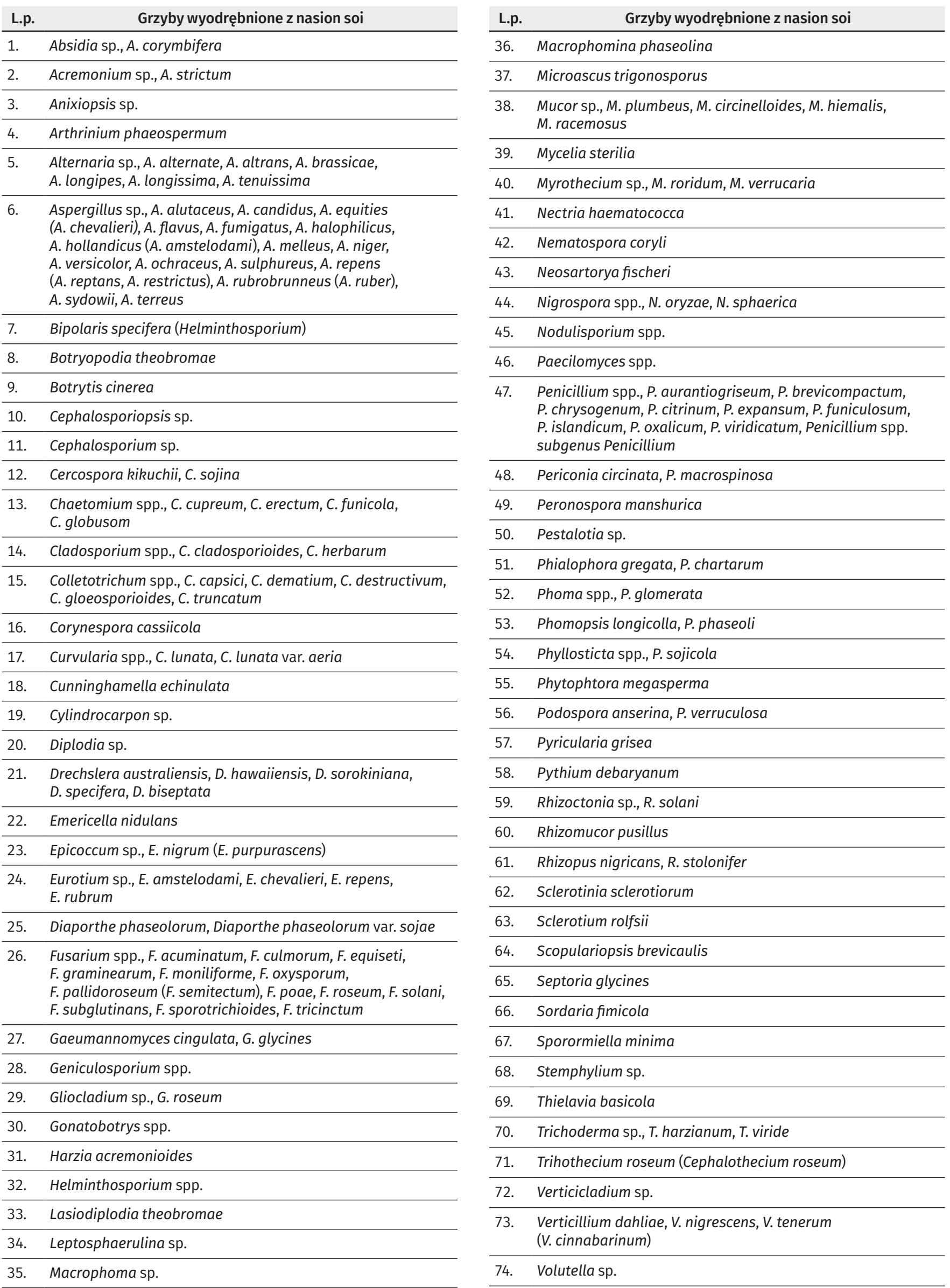


3. Hadanich D., Juhasz-Roman M., Nagy B.: The effect of microorganisms deteriorating quality in storing sunflower seed. Acta Alimentaria. 2008, 37 (1), 77-86.

4. Horoszkiewicz-Janka J.,Jajor E., Korbas M.: Wpływ grzybów toksynotwórczych na wybrane cechy jakościowe plonu zbóż i rzepaku. Prog Plant Prot Post Ochr Roślin. 2008, 48 (3), 1039-1047.

5. Krysińska-Traczyk E., Kiecana I., Perkowski J., Dutkiewicz J.: Levels of fungi and mycotoxins in samples of grain and grain dust collected on farms in eastern Poland. Ann Agric Environ Med. 2001, 8 (2), 269-274.

6. Krysińska-Traczyk E., Perkowski J., Dutkiewicz J.: Levels of fungi and mycotoxins in the samples of grain and grain dust collected from five various cereal crops in eastern Poland. Ann Agric Environ Med. 2007, 14 (1), 159-167.

7. Hashmi F.M., Ghaffar A.: Seed-borne mycoflora of wheat, sorghum and barley. Pakistan J Bot. 2006, 38 (1), 185-192.

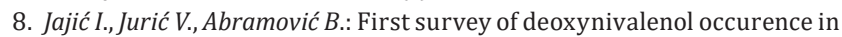
crops in Serbia. Food Control. 2008, 19, 545-550.

9. Tabuc C., Marin D., Guerre P., Sesan T., Bailly J.D.: Molds and mycotoxin content of cereals in southeastern Romania. J Food Prot. 2009, 71 (3), 662-665.

10. Berghofer L.K., Hocking A.D., Miskelly D., Jansson E.: Microbiology of wheat and flour milling in Australia. Int J Food Microbiol. 2003, 85 (1-2), 137-149.

11. Niaz I., Dawar S.: Detection of seed borne mycoflora in maize (Zea mays L.). Pakistan J Bot. 2009, 41 (1), 443-451.

12. Kumar V., Basu M.S., Rajendran T.P.: Mycotoxin research and mycoflora in some commercially important agriculture commodities. Crop Prot. 2008, 27 (6), 891-905.

13. Silva C.F., Schwan R.F., Dias E.S., Wheals A.E.: Microbial diversity during maturation and natural processing of coffee cherries of Coffea arabica in Brazil. Int J Food Microbiol. 2000, 60 (2-3), 251-260.

14. Batista L.R., Chalfoun S.M., Prado G., Schwan R.F., Wheals A.E.: Toxigenic fungi associated with processed (green) coffee beans (Coffea arabica L.). Int J Food Microbiol. 2003, 85 (3), 293-300.

15. Mounjouenpou P., Gueule D., Fontana-Tachon A., Guyot B., Tondje P.R., Guiraud $J . P .:$ Filamentous fungi producing ochratoxin a during cocoa processing in Cameroon. Int J Food Microbiol. 2008, 121 (2), 234-241.

16. Sánchez-Hervás M., Gil J.V., Bisbal F., Ramon D., Martínez-Culebras P.V.: Mycobiota and mycotoxin producing fungi from cocoa beans. Int J Food Microbiol. 2008, 125 (3), 336-340.

17. Aliyu B.S., Kutama A.S.: Isolation and identification of fungal flora associated with groundnut in different storage facilities. Sci World J. 2007, 2 (2), 34-36.

18. Khosravi A.R., Shokri H., Ziglari T.: Evaluation of fungal flora in some important nut products (pistachio, peanut, hazelnut and almond) in Tehran, Iran. Pak J Nutr. 2007, 6 (5), 460-462.

19. Singh P.K., Shukla A.N.: Survey of mycoflora counts, aflatoxin production and induced biochemical changes in walnut kernels. J Stored Prod Res. 2008, 44, 169-172.

20. Youssef M.S., El-Maghraby O.M.O., Ibrahim Y.M.: Mycobiota and mycotoxins of Egyptian peanut (Arachis hypogeae) seeds. Int J Bot. 2008, 4 (4), 349-360.

21. Janda K., Ulfig K.: Badania składu ilościowego i jakościowego grzybów w suszach roślin leczniczych. Rocz Państw Zakł Hig. 2005, 56 (4), 331-338.

22. Janda K., Ulfig K.: A comparison of selected media and incubation temperatures for isolation of microscopic fungi from dried medicinal plants. Rocz Państw Zakł Hig. 2006, 57 (3), 267-276.

23. Mandeel Q.A.: Fungal contamination of some imported spices. Mycopathologia. 2005, 159 (2), 291-298.

24. Khan S.N., Riaz T., Hannan A., Mukhtar I.: Fungal contamination of medicinal herbs during commercial storage in Punjab. Mycopathologia. 2006, 4 (1), 21-25.

25. Abou Donia M.A.: Microbiological quality and aflatoxinogenesis of Egyptian spices and medicinal plants. Global Veterinaria. 2008, 2 (4), 175-181.

26. Koul A., Sumbali G.: Detection of zearalenone, zearalenol and deoxynivalenol from medicinally important dried rhizomes and root tubers. Afr Biotechnol. 2008, 7 (22), 4136-4139.

27. Laugauskas A., Stakeniene J.: Toxin producing micromycetes of fruit, berries and vegetables. Ann Agric Environ Med. 2002, 9, 183-197.

28. Alghalibi S.M.S., Shater A.R.M.: Mycoflora and mycotoxin contamination of some dried fruits in Yemen Republic. Ass Univ Bull Environ Res. 2004 7 (2), 19-25.

29. Dymić G.R., Maletić Z.M., Kocić-Tanackov S.D.: Xerotolerant mycopopulations and mycotoxins in muesli components. Proc Nat Sci Matica Srpska Novi Sad. 2005, 109, 81-87.
30. Laugauskas A., Repečkiene J., Novosinskas H.: Micromycetes, producers of toxins, detected on stored vegetables. Ann Agric Environ Med. 2005, 12 (2), 253-260.

31. Moss M.O.: Fungi, quality and safety issues in fresh fruits and vegetables. J Appl Microbiol. 2008, 104 (5), 1239-1243.

32. Hell K., Gnonlonfin B.G., Kodjogbe G., Lamboni Y., Abdourhamane I.K.: Mycoflora and occurrence of aflatoxin in dried vegetables in Benin, Mali and Togo, West Africa. Int J Food Microbiol. 2009, 135 (2), 99-104.

33. Korniłowicz-Kowalska T., Szwed A., Szwed G.: Charakterystyka mykologiczna nasion rzepaku w zależności od warunków ich przechowywania. Acta Agrophysica. 2008, 37, 83-93.

34. Roy K.W., Baird R.E., Abney T.S.: A review of soybean (Glycine max) seed, pod and flower mycofloras in North America, with methods and a key for identification of selected fungi. Mycopathologia. 2000, 150 (1), 15-27.

35. Bhattacharya K., Raha S.: Deteriorative changes of maize, groundnut and soybean seeds by fungi in storage. Mycopathologia. 2002, 55 (3), 135-141.

36. Pacin A.M., Gonzales H.H., Etcheverry M., Resnik S.L., Vivas L., Espin S.: Fungi associated with food and feed commodities from Ecuador. Mycopathologia. 2002, 156 (2), 87-92.

37. Kacaniova M.: Feeding soybean colonization by microscopic fungi. Trakya Univ J Sci. 2003, 4 (2), 165-168.

38. Nasir N.: Detecting seed borne fungi of soybean by different incubation methods. Pak J Plant Path. 2003, 2 (2), 114-118.

39. Pozzi C.R., Braghini R., Arcaro J.R., Zorzete P., Israel A.L., Pozar I.O. et al.: Mycoflora and occurrence of alternariol and alternariol monomethyl ether in Brazilian sunflower from sowing to harvest. J Agric Food Chem. 2005, 53 (14), 5824-5828.

40. Sharfun-Nahar M.M., Mushtaq M., Hashmi M.H.: Seed-borne mycoflora of sunflower (Helianthus annuus L.). Pakistan J Bot. 2005, 37 (2), 451-457.

41. Brazauskienie I., Petraitiene E., Makeviciene A.: Effects of genotype and environmental factors on rape seed contamination with mycotoxins and mycotoxin-producing fungi. Ekologija. 2006, 3, 14-20.

42. Broggi L.E., Gonzales H.H., Resnik S.L., Pacin A.: Alternaria alternata prevalence in cereal grains and soybean seeds from Entre Rios, Argentina. Rev Iberoam Micol. 2007, 24 (1), 47-51.

43. Medić-Pap S., Milošević M., Jasnić S.: Soybean seed-borne fungi in the Vojvodina province. Phytopathol Pol. 2007, 45, 55-65.

44. Raj M.H., Niranjana S.R., Nayaka S.C., Shetty H.S.: Health status of farmers saved paddy, sorghum, sunflower and cowpea seeds in Karnataka, India. World J Agric Sci. 2007, 3 (2), 167-177.

45. Ezekiel C.N., Odebode A.C., Fapohunda S.O.: Zearalenon production by naturally occurring Fusarium species on maize, wheat and soybean from Nigeria. J Biol Environ Sci. 2008, 2 (6), 77-82.

46. Haikal N.Z.: Effect of filtrates of pathogenic fungi of soybean on seed germination and seedling parameters. J Appl Sci Res. 2008, 4 (1), 48-52.

47. Samson R.A., Hoekstra E.S., Frisvad J.C., Filtenborg O.: Introduction to foodand airborne fungi. Centraalbureau voor Schimmelcultures, Utrecht 2000.

48. Cooney D.G., Emerson R.: Thermophilic fungi. An account of their biology, activities and classification. W.H. Freeman and Company, San FranciscoLondon 1964.

49. Raper K.B., Fennel K.D.: The genus Aspergillus. Krieger Publishing Company, Huntington-New York 1977.

50. Domsch K.H., Gams W., Anderson T.H.: Compendium of soil fungi. Academic Press, London-San Francisco 1980.

51. Hoog de G.S., Guarro J., Gene J., Figueras M.J.: Atlas of clinical fungi. $2^{\text {nd }}$ Edition. Centraalbureau voor Schimmelcultures \& Universitat Rovira i Virgili, Utrecht-Reus 2000.

52. Klich M.A.: Identification of common Aspergillus species. Centraalbureau voor Schimmelcultures, Utrecht 2000.

53. Samson R.A., Pitt J.I.: Integration of modern taxonomic methods for Penicillium and Aspergillus classification. Harwood Publishers, Amsterdam 2000.

54. Frisvad J.C., Samson R.A.: Polyphasic taxonomy of Penicillium subgenus Penicillium. A guide to identification of food and air-borne terverticillate Penicillia and their mycotoxins. Stud Mycol. 2004, 49, 1-174.

55. Samson R.A., Frisvad J.C.: Penicillium subgenus Penicillium: new taxonomic schemes and mycotoxins and other extrolites. Centraalbureau voor Schimmelcultures, Utrecht 2004

56. Prochacki H.: Podstawy mikologii lekarskiej. PZWL, Warszawa 1975

57. Hesseltine C.W., Rogers R.F., Bothast R.J.: Microbiological study of exported soybeans. Cereal Chem. 1978, 55 (3), 332-340. 
58. El-Kady I.A., Youssef M.S.: Survey of mycoflora and mycotoxins in Egyptian soybean seeds. J Basic Microbiol. 1993, 33 (6), 371-378.

59. Tseng T.C., Tu J.C., Soo L.C.: Comparison of the profiles of seedborne fungi and the occurrence of aflatoxins in mould damaged beans and soybean. Microbios. 1995, 84 (339), 106-116.
60. Weidenbörner M.: The mycoflora of soybean seeds in relation to the used plating medium GD18 or MSA. Nahrung. 1997, 41 (4), 239-240.

61. Dhingra O.D., Jham G., Napoleão I.T.: Ergosterol accumulation and oil quality changes in stored soybean invaded by Aspergillus rubber (A. glaucus group). Mycopathologia. 1998, 143, 85-91. 